\title{
Erratum to: Blood lead and cadmium levels and renal function in Korean adults
}

\author{
Sungjin Chung $\cdot$ Jong Hee Chung $\cdot$ Sung Jun Kim • \\ Eun Sil Koh · Hye Eun Yoon · Cheol Whee Park • \\ Yoon Sik Chang $\cdot$ Seok Joon Shin
}

Published online: 24 May 2014

(C) Japanese Society of Nephrology 2014

\section{Erratum to: Clin Exp Nephrol \\ DOI 10.1007/s10157-013-0913-6}

Errors appeared in this article, unfortunately.

In the Results section, in the second sentence, the "greater than" and "less than" symbols were reversed. The sentence should read as follows:

Mean eGFR was $90.0 \pm 0.7 \mathrm{ml} / \mathrm{min} / 1.73 \mathrm{~m}^{2}$, and mean eGFR in participants $<65$ and $>65$ years old were $92.9 \pm 0.8$ and $71.5 \pm 1.1 \mathrm{ml} / \mathrm{min} / 1.73 \mathrm{~m}^{2}$, respectively.

In Table 1, some incorrect values were inadvertently entered. The correct Table 1 is as follows.

The online version of the original article can be found under doi:10.1007/s10157-013-0913-6.

S. Chung · S. J. Kim · E. S. Koh · H. E. Yoon ·

C. W. Park · Y. S. Chang · S. J. Shin

Division of Nephrology, Department of Internal Medicine,

College of Medicine, The Catholic University of Korea, 222,

Banpo-daero, Seocho-gu, Seoul 137-701, Republic of Korea

J. H. Chung

Department of Statistics, The Graduate School of Ewha Womans University, 52, Ewhayeodae-gil, Seodaemun-gu, Seoul 120-750,

Republic of Korea

\section{S. J. Shin ( $($ )}

Division of Nephrology, Department of Internal Medicine,

Incheon St. Mary's Hospital, The Catholic University of Korea,

56, Dongsu-ro, Bupyeong-gu, Incheon 403-720,

Republic of Korea

e-mail: imkidney@catholic.ac.kr 
Table 1 Characteristics of participants stratified by estimated glomerular filtration rate and proteinuria status

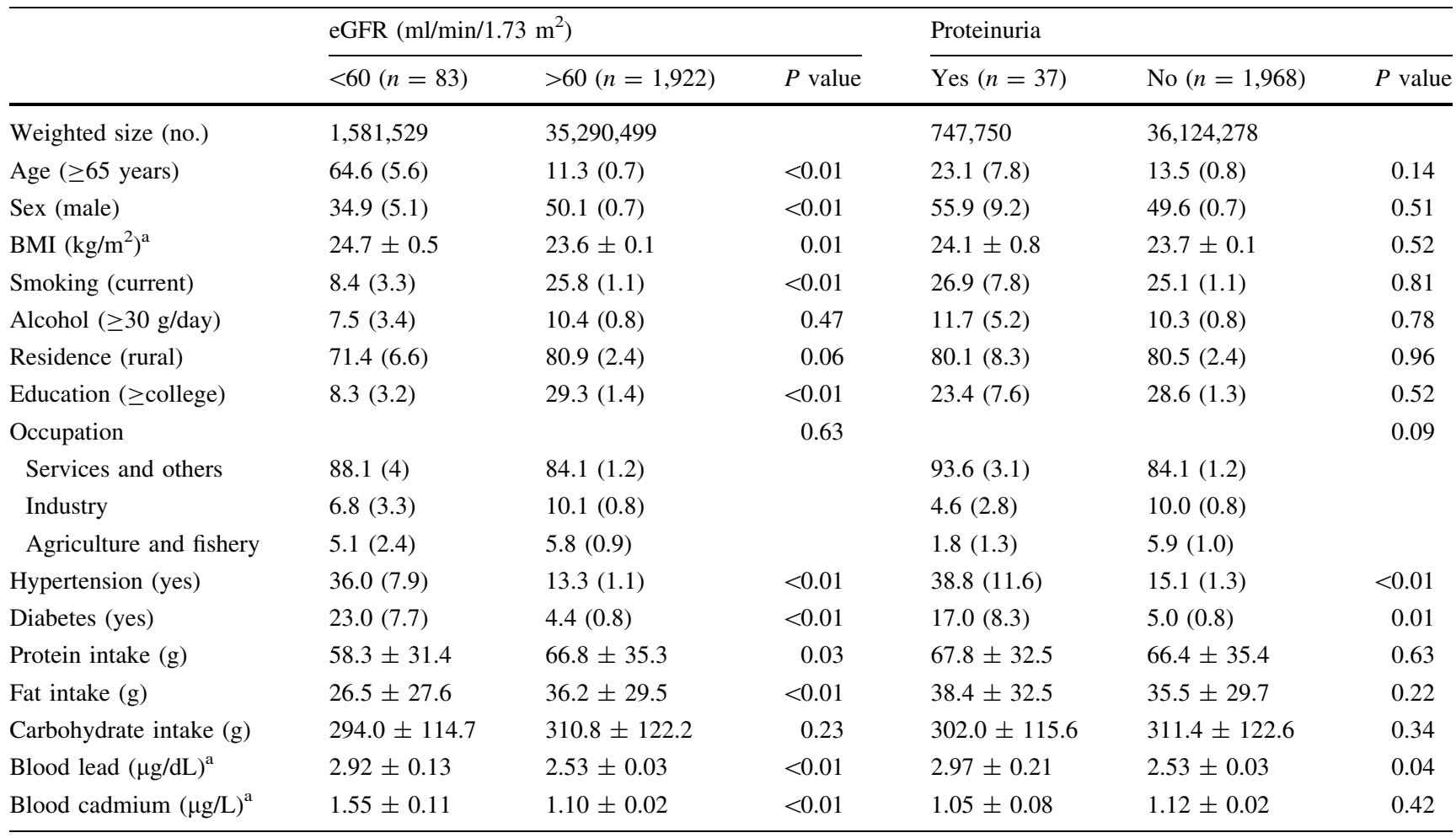

Values are expressed as percent (standard error)

eGFR estimated glomerular filtration rate, $B M I$ body mass index

${ }^{a}$ Values are expressed as mean (standard error) 